\title{
Posttraumatic stress disorder diagnostic criteria and suicidal ideation in a South African Police sample
}

\author{
R Steyn', N Vawda ${ }^{2}$, GE Wyatt ${ }^{3}$, JK Williams ${ }^{3}$, SN Madu ${ }^{4}$ \\ ${ }^{1}$ Graduate School of Business Leadership, University of South Africa, Midrand, South Africa \\ 2Department of Behavioural Medicine, Nelson R. Mandela School of Medicine, University of KwaZulu-Natal, Durban, South Africa \\ ${ }^{3}$ Department of Psychiatry and Biobehavioral Sciences, University of California, Los Angeles, California, United States of America \\ 4Faculty of Social Sciences, Anambra State University, Igbariam Campus, Anambra State, Nigeria
}

\begin{abstract}
Objective: Exposure to traumatic events may precipitate suicidal ideation. Once an individual is diagnosed with PTSD, a suicide risk assessment often follows. This study explores how PTSD symptom criteria correlate with suicidal ideation in a sample of police officers. While the psychometric measures of PTSD often mirror the DSM-IV-TR criteria, focusing on exposure, symptom, and duration criteria, suicidal ideation measures often focus on concepts quite different from that. In this report the focus was on investigating how PTSD symptom criteria correlate with the suicidal ideation. Method: A group of South African police officers ( $N=217$ ) were assessed by means of the Posttraumatic Diagnostic Scale and a short version of the Adult Suicide Ideation Questionnaire. Linear and hierarchical regressions were used to determine which PTSD symptom criteria best predict suicidal ideation. Results: Hyperarousal was the primary predictor of suicidal ideation ( $R^{2}$ [adjusted] $=0.249$ ). Intrusive thoughts added only marginally to the model, contributing a further $2.5 \%$ to the declared variance. The contributions of the other two symptom types were negligible. Conclusion: In this study hyperarousal correlated significantly with suicidal ideation. It is suggested that practitioners be alert to these symptoms as possible indicators of suicidal ideation. Implications for suicide risk assessment and prevention measures are discussed.
\end{abstract}

Keywords: Stress Disorders; Post-Traumatic; Suicidal ideation; Police; South Africa

Received: 18-02-2011

Accepted: $28-09-2011$

doi: http://dx.doi.org/10.4314/ajpsy.v16il.3

\section{Introduction}

Posttraumatic stress disorder (PTSD) is characterised by a constellation of symptoms, which may be distressing and impairing, after experiencing or being confronted with a traumatic event that includes an actual or perceived threat to self or others. ${ }^{1}$ Symptoms involve repeated and intrusive memories related to the trauma (e.g., thoughts, dreams or nightmares), avoidance of situations reminiscent of the trauma, and hyperarousal (e.g., sleep difficulties, irritability, reduced concentration, hypervigilance and exaggerated startle response).

While reports on prevalence rates for the general population range from 7 to $12 \%$, studies of "at risk" populations, such as combat veterans, demonstrate higher rates of PTSD. ${ }^{2}$ Significant associations between witness and perpetrator violence and suicidal ideation have also been established. ${ }^{3}$

\section{Correspondence}

Dr N Vawda

Department of Behavioural Medicine, UKZN, 3rd Floor, George Campbell Building, Howard College Campus, Durban, 4013, South Africa

email: vawdan@yahoo.com
It has been posited that exposure to trauma may be an important potential environmental contributor to suicidal behaviour. ${ }^{3}$ In a review of the literature, a clear relationship was reported between PTSD and suicidal thoughts and behaviours, irrespective of the type of trauma experienced. ${ }^{4}$ It has been suggested that PTSD has a strong association with suicidality, predicting subsequent suicidal attempts. ${ }^{5}$

However, despite accumulating evidence regarding increased risk for suicidal behaviour among individuals with a history of trauma and a diagnosis of PTSD, increased suicide risk is hardly mentioned in the trauma literature. Similarly, PTSD is rarely mentioned as a risk factor in literature on suicide. ${ }^{6}$

While police officers are considered a high risk group for suicide, very little research has been conducted with this group in general. ${ }^{7}$ This study attempts to address which aspects of PTSD are correlated with suicidal ideation, as not all individuals with PTSD develop suicidal ideation or make such attempts. These data may assist in guiding more rigorous assessments of suicidal ideation in PTSD patients, as well as in the diagnosis and management thereof.

It is important to explore the relationship between PTSD and suicidal ideation, especially within developing, low-income 
countries where trauma may be more prevalent and manifest differently than in developed countries. ${ }^{3}$ Also, attention must be placed on groups that are most vulnerable to trauma experiences. One such high-risk group is police officers in South Africa, who are exposed to traumatic events as part of their occupation and whose repeated exposure to traumatic on-the-job experiences may lead to psychological problems such as PTSD. ${ }^{7}$ Police officers are also exposed to stress inherent in their jobs which is considered customary, but which exceeds stress inherent in most other professions. ${ }^{7-10}$ Furthermore, the crime rate in South Africa is high, with approximately 2.1 million serious cases being reported to the police for the year April 2009 to March 2010. Additionally, police officers have become targets of criminal attacks, with 107 being killed in the line of duty in the same period. ${ }^{11}$ This perceived stress is associated with anxiety, somatisation, depression and PTSD. ${ }^{7}$

High rates of suicide have been reported in the South African Police Service (SAPS), with an average suicide rate of 74.5 per 100 000 for the period 01 January 1994 to 31 December 2006. ${ }^{12}$ This is far higher than the suicide figures provided by the World Health Organisation (16/100 000) ${ }^{13}$ and the South African Department of Health (17.4/100 000). ${ }^{14}$ The SAPS rates are also higher than those reported by other international law enforcement agencies. ${ }^{15-17}$

The aim of the study was to examine the possible link between PTSD and suicidal ideation in a representative sample of SAPS officers in Limpopo (a province of South Africa), and to identify whether specific posttraumatic stress symptoms predict suicidal ideation.

\section{Method \\ Design}

A cross-sectional survey design was chosen for the research design. This design is suitable for describing the population as well as the calculation of correlations between measured constructs. ${ }^{18}$ After interviewees were informed and consented to the research process, the data were collected through one-on-one interviews in a private room by a trained interviewer.

\section{Ethics}

Ethical approval for this research was obtained from the Institutional Review Board of the University of California, Los Angeles (UCLA IRB \# G07-08-091-01).

\section{Sample}

Permission was obtained from the Provincial Commissioner of the South African Police Service in Limpopo province to recruit confidentially and anonymously a representative sample of police officers from all ranks of operational officers in that province. A representative sample of 300 officers, from all ranks, was randomly extracted from a list containing names of all operational police officers in Limpopo province (+/- 10000 officers), one of the rural provinces of South Africa.

\section{Measurement instruments}

Two instruments were used, one measuring PTSD symptoms and the other suicidal ideation.

1. The Posttraumatic Diagnostic Scale (PDS) ${ }^{19}$ is often used to diagnose PTSD and has five items on intrusive thoughts, seven on avoidance and numbing, five on hyperarousal, and nine on associated problems. The first question on intrusive thoughts, for example, reads as follows: "In the past month, did you have upsetting thoughts or images about the traumatic event that came into your mind when you didn't want them to?" The response format was as follows: 0 - Not at all; 1 - Once a week or less / once in a while; 2 - 2 to 4 times a week / half the week; 3 - 5 or more times a week / almost always. On the associated problems the response format was either yes (1) or no (0). The scores ranged from 0 to 15 for both intrusive thoughts and hyperarousal, 0 to 21 for avoidance and numbing, and 0 to 9 for associated problems. PTSD symptom severity scores can be derived by summing the ratings of the symptoms. ${ }^{19}$ The PDS total symptom severity scale demonstrates high internal consistency (Alpha = 0.92), test-retest reliability (0.83), convergent validity with other measures of PTSD diagnosis and severity (Structured Clinical Interview for DSM-III-R-Patient, kappa $=0.65,82 \%$ agreement between the measures), and concurrent validity (with the State-Trait Anxiety Inventory). 19,20

2. An adapted short measure of suicidal ideation with 10 items from the Adult Suicidal Ideation Questionnaire was utilised. ${ }^{21}$ The first question reads as follows: "Did you, at least once in the past month, think about killing yourself?" The no (0) / yes (1) response format resulted in a score range of 0 to 10.22 The reported internal consistency of the instrument was acceptable, varying from 0.96 to $0.98 .23,24$ The test differentiated significantly between suicide attempt and psychiatric control group..$^{24}$ The test-retest reliability varies between 0.86 and 0.95 , and evidence for the content, construct and criterionrelated validity is avaliable. ${ }^{21,22}$

\section{Statistical analysis}

In order to achieve the empirical aim of this research, linear and hierarchical regressions were calculated. The Statistical Package for the Social Sciences (SPSS), Version 17, was used.

\section{Results}

\section{Demographics of the sample}

From the 300 South African Police Service (SAPS) employees approached to participate in the study, 217 completed interviews were captured. The main reason provided for not participating in the study was the unavailability due to operational commitments. Of the participants 161 , or $74.2 \%$, were male and 56 , or $25.8 \%$, were female. The average age of the respondents was 40 years, with a standard deviation of 8.26 years. The oldest respondent was born in 1951 and the youngest in 1985. Just more than half of the respondents ( $\mathrm{n}=114,51.8 \%$ ) had completed high school (grade 12). A large proportion had completed grade 10 ( $n=89,40.5 \%)$, while a small proportion ( $\mathrm{n}=11,5.2 \%$ ) had a lower educational level (various grades). The lowest educational level was grade 6 . Most respondents (194 or 89.4\%) had an annual income of less than R150 000, with only 23 or 10.6\% earning more than that amount. All the respondents were involved in operational police work in the Limpopo province. No data on race or ethnicity were collected, as the envisaged small group sizes would not have allowed for the use of inferential statistics.

\section{Reliability}

The reliability of the PTSD symptom measures, expressed as Cronbach's alpha coefficient, was 0.854 ( $n=213 ; 5$ items) for intrusive thoughts, 0.835 ( $\mathrm{n}=213$; 7 items) for avoidance and numbing, 0.821 ( $\mathrm{n}=214 ; 5$ items) for hyperarousal, and 0.915 ( $\mathrm{n}=$ 213; 9 items) for associated problems. The reliability of the suicidal ideation measure was 0.805 ( $n=217 ; 10$ items). The reliability of the measures was acceptable. ${ }^{25}$ 


\section{PTSD symptoms and suicidal ideation}

The average score on intrusive thoughts were 2.09 (std. dev. $=2.85$; range 0 to 15), for avoidance and numbing 3.03 (std. dev. = 4.09; range 0 to 21), for hyperarousal 2.15 (std. dev. $=2.93$; range 0 to 15), and for associated problems 1.23 (std. dev. $=2.42$; range 0 to 9). The total score for suicidal ideation was 0.57 (std. dev. = 1.38; range 0 to 9 ).

In model 1 of Table I the results of a linear regression with suicidal ideation as the dependent variable and the four symptom groupings are presented. In this model the $\mathrm{R}^{2}$ (adjusted) $=0.281(\mathrm{R}$ $=0.543 ; \mathrm{R}^{2}=0.294 ;$ SE of estimate $\left.=1.178\right)$.

In respect of model 2 and model 3, the SPSS software was used to remove variables from the regression equation automatically in a stepwise manner. In model 2 only one independent variable was included, namely hyperarousal. In this model the $\mathrm{R}^{2}$ (adjusted) = $0.249\left(R=0.503 ; R^{2}=0.253 ;\right.$ SE of estimate = 1.203). In model 3 hyperarousal and intrusive thoughts were included. In model 3 the $\mathrm{R}^{2}($ adjusted $)=0.274\left(\mathrm{R}=0.531 ; \mathrm{R}^{2}=0.282 ; \mathrm{SE}\right.$ of estimate $=$ 1.182).

From the aforementioned (see model 2) it can be read that almost 25\% (24.9) of the variance in the suicidal ideation score is described by the hyperarousal scores. Adding intrusive thoughts to the equation improved the predictive value of the model with $2.5 \%$ to declare $27.4 \%$ of the variance (see model 3). Adding the other two variables to the model increases the predictive power by an additional $0.7 \%$ (see model 1 ).

A model was also tested where gender was added as a variable to the four PTSD symptom scores. In this model the $\mathrm{R}^{2}$ (adjusted) $=0.285\left(R=0.550 ; R^{2}=0.302 ;\right.$ SE of estimate $\left.=1.186\right)$, with gender adding only 0.004 to model 1 .

\section{Discussion}

The purpose of this study was to examine a possible link between PTSD and suicidal ideation and to examine whether there are any specific posttraumatic symptoms that predict suicidal ideation. This study may be the first attempt to identify the characteristics of PTSD that may relate to suicidal ideation in a random sample of active police officers in South Africa. The findings of this study address issues raised in current literature 4 in terms of whether there are stronger relationships between any one of the three PTSD symptom clusters and suicidality compared to the other criteria.
Similar to other studies ${ }^{27,28}$, this study demonstrated that there are certain PTSD criteria that predict suicidal ideation. Hyperarousal was a key factor, and to a lesser extent intrusive thoughts predicted suicidal ideation in this sample. The findings of this study are in line with the findings of earlier researchers who found a relationship between hyperarousal and suicidal risk ${ }^{27}$ and between intrusive thoughts and suicidal ideation. ${ }^{28}$

Neither avoidance, numbing, or associated impairment influenced the relationship significantly. Gender also had no significant effect on the relationship.

The finding that hyperarousal is a key predictor of suicidal ideation and possible suicide risk has been interpreted as a problem in impulse control and affect regulation. ${ }^{26}$ This link is made because hyperarousal is characterised by symptoms that implies problems of control and regulation of impulses, such as hypervigilance, sleep difficulties, outbursts and extreme reactions to sudden noises. ${ }^{1}$ These findings suggest that arousal and impulsivity may heighten suicide risk. It is possible that those who act impulsively may be more likely to act on suicidal ideation, but this relationship awaits further study.

Possibilities are that individuals who do not engage in avoidance (which is not a significant predictor in this sample) are continually subjected to intrusive thoughts. Intrusive PTSD symptoms produce higher levels of subjective distress which, when heightened enough, activate a flight from intolerable stress through thoughts of self-destruction. ${ }^{27}$ These findings confirm that intrusive thoughts, rather than avoidance, as found in this study, should relate to suicidal ideation.

Police officers and those involved in combat related exposure such as military personnel are trained to be on high alert. Suicidal individuals are characterised by constantly monitoring their interpersonal environment for danger. 4 These behaviours may become second nature to them and when combined with repeated and prolonged exposure ${ }^{6}$, may result in a constant state of high alarm. If the alarm state is elicited too intensely or frequently over an extended period, the energy needed for a return to equilibrium may become depleted, leading to exhaustion. ${ }^{28}$

Regardless of gender, it has also been reported that police officers have a "superman" mentality and a macho image which they try to protect. ${ }^{8}$ To compound matters, males, the largest group of employees in the SAPS, often do not seek help and it is often a

\begin{tabular}{|c|c|c|c|c|c|c|}
\hline & & Unstand & coefficients & Standardised coefficients & & \\
\hline $\begin{array}{l}\text { Dependent variable: } \\
\text { Suicidal Ideation }\end{array}$ & & $B$ & SE & Beta & $t$ & $p$ \\
\hline Model 1 & $\begin{array}{l}\text { (Constant) } \\
\text { Intrusive thoughts } \\
\text { Avoidance \& Numbing } \\
\text { Hyperarousal } \\
\text { Problems }\end{array}$ & $\begin{array}{l}-0.014 \\
0.076 \\
0.032 \\
0.119 \\
0.064\end{array}$ & $\begin{array}{l}0.104 \\
0.043 \\
0.033 \\
0.045 \\
0.045\end{array}$ & $\begin{array}{l}0.155 \\
0.095 \\
0.250 \\
0.122\end{array}$ & $\begin{array}{l}-0.138 \\
1.747 \\
0.971 \\
2.652 \\
1.428\end{array}$ & $\begin{array}{l}0.890 \\
0.082 \\
0.333 \\
0.009 \\
0.155\end{array}$ \\
\hline Model 2 & $\begin{array}{l}\text { (Constant) } \\
\text { Hyperarousal }\end{array}$ & $\begin{array}{l}0.068 \\
0.239\end{array}$ & $\begin{array}{l}0.101 \\
0.028\end{array}$ & 0.503 & $\begin{array}{l}0.677 \\
8.532\end{array}$ & $\begin{array}{l}0.499 \\
0.000\end{array}$ \\
\hline Model 3 & $\begin{array}{l}\text { (Constant) } \\
\text { Hyperarousal } \\
\text { Intrusive thoughts }\end{array}$ & $\begin{array}{l}-0.011 \\
0.171 \\
0.108\end{array}$ & $\begin{array}{l}0.103 \\
0.036 \\
0.037\end{array}$ & $\begin{array}{l}0.361 \\
0.221\end{array}$ & $\begin{array}{l}-0.105 \\
4.783 \\
2.933\end{array}$ & $\begin{array}{l}0.916 \\
0.000 \\
0.004\end{array}$ \\
\hline
\end{tabular}


challenge to identify suicidal men if they do not present themselves for help. ${ }^{29,30}$ An awareness of the link between PTSD related hyperarousal and suicidal ideation may increase the number of employees identified as at risk for suicide.

While these findings contribute to what we know about the contribution of PTSD symptoms to suicidal ideation, there are limitations to this study. Police officers were not screened for depression, which may have affected these results. In many PTSD studies, suicidality is associated with co-morbid depression. The presence of co-morbid depression appears to boost the effect of PTSD on suicidality. ${ }^{4,5}$ It has also been reported that when depression was controlled, it weakened but did not eliminate the relationship, leading researchers to conclude that depression plays a mediating role. ${ }^{6}$ Pre-trauma personality, borderline personality traits as well as other personality traits, such as perfectionism, may contribute to an increased risk of suicide in patients suffering from PTSD $^{6}$, and these have not been explored in this study. While the issue of rank in the police has also not been explored in this study, and is unlikely to impact on the results, as other research 8,9 has found no relationship between rank and stress symptoms (suicidal behaviour is often linked to the presence of stress symptoms ${ }^{31}$ ). Also, we did not examine for racial and ethnic differences which prevent the identification of possible health disparities. It will be important for future research to explore such differences, as well as assess whether cultural differences influences appraisal of traumatic experiences and coping strategies. The final limitation is that the findings are specific to police officers and may not be generalisable to other community samples not involved in law enforcement.

\section{Conclusion}

The findings of this study have important implications for the treatment and management of police officers at risk for PTSD. The study results indicate that there are certain PTSD criteria that can predict suicidal ideation. When individuals present with PTSD, practitioners should be aware that high levels of hyperarousal and, to a lesser extent, intrusive thoughts, which may point towards suicidal ideation. Practitioners should fully and routinely explore these symptoms of PTSD and their possible link to suicidality in their assessments of police officers. This can minimise negative and destructive outcomes associated with suicidal ideation. It is recommended that future studies should not only treat PTSD symptoms holistically as a possible predictor of suicidal behaviour, but examine symptom clusters separately when assessing for suicidality, as the mentioned criteria are central to the prediction of suicidal ideation.

\section{Acknowledgement}

This research was supported in part by the Fogarty Grant 3 D43 TW007278.

\section{References}

1. American Psychiatric Association. Diagnostic and statistical manual for mental disorders, 4th edition, text revision (DSM-IV-TR). Washington, DC: Author; 2000.

2. Sareen J, Stein MB, Afifi TO, Fleet C, Amundsen GJG. Physical and mental comorbidity, disability, and suicidal behaviour associated with posttraumatic stress disorder in a large community sample. Psychosomatic Medicine 2007; 69: $242-248$

3. Stein D, Chiu WT, Hwang I, Kessler RC, Sampson N, Alonso J, et al. (2010). Crossnational analysis of the associations between traumatic events and suicidal behaviour: Findings from the WHO World Mental Health Surveys. PLOS ONE. 2010; 5(5): e10574. doi:10.1371/journal.pone.0010574; 2010.
4. Pangioti $M$, Gooding P, Tarrier N. Post-traumatic stress disorder and suicidal behaviour: A narrative review. Clinical Psychology Review 2009; 29(6): 471-482.

5. Lönnqvist J. Major psychiatric disorders in suicide and suicide attempters. In: Wasserman D, Wasserman C, editors. Oxford textbook of suicidology and suicide prevention. Oxford: Oxford University Press; 2009.

6. Krysinska K, Lester D. Post-traumatic stress disorder and suicide risk: A systematic review. Archives of Suicide Research 2010; 14: 1-23.

7. Violanti JM, Castellano C, O'Rourke J, Paton D. Proximity to 9/11 terrorist attack and suicidal ideation in police officers. Traumatology 2006; 12(3): 248-254.

8. Madu SN, Poodhun SEA. Stress and substance use among police officials in the central region of Limpopo province. Journal of Social Sciences 2006; 12(3): 213-224.

9. Alexander C. Police psychological burnout and trauma. In: Violanti J, Paton D, editors. Police trauma: Psychological aftermath of civilian combat. Springfield, IL: Charles C. Thomas; 1999.

10. Gershon RM, Lin S, Li X. Work stress in aging police officers. Journal of Occupational and Environmental Medicine 2002; 44: 160-167.

11. The crime situation in South Africa [internet] 2010 [cited 2010 Nov 28]. Available from: http://www.sap.s.gov.za/statistics/reports/crimestats/2010/crime_stats.htm

12. Steyn $R$. The effect of multiple organisational interventions on suicide behaviour. Proceedings of PICMET 2008; 2008 Jul 27-31; Cape Town, South Africa.

13. World Health Organisation. Suicide prevention [internet] 2008 [cited 2010 Nov 28] Available from: http://www.who.int/mental_health/ prevention/suicide/suicideprevent/en/

14. Department of Health. Non-natural mortality surveillance: Focus on suicide in South Africa. Statistical notes [internet] 2000 [cited 2011 Feb 2]; 2(13): 1-6. Available from: http://www.doh.gov.za/facts/stats-notes/2000/stat13-00.html

15. Hackett DL. Suicide and the police. In: Hackett DP, Violanti JM, editors. Police suicide: Tactics for prevention. Springfield, IL: Thomas; 2003

16. Loo R. Police suicide: The ultimate stress reaction. In: Violanti J, Paton D, editors. Police trauma: Psychological aftermath of civilian combat. Springfield, IL: Thomas; 1999.

17. Violanti JM. Police suicide: Tactics for prevention. In: Hackett DP, Violanti JM, editors. Police suicide: Tactics for prevention. Springfield, IL: Thomas; 2003.

18. Shaughnessy JJ, Zechmeister EB, Zechmeister JS. Research methods in psychology. 8th ed. New York, NY: McGraw-Hill; 2009.

19. Foa EB. The posttraumatic diagnostic scale (PDS) manual. Minneapolis, MN National Computer Systems; 1995.

20. Foa EB, Cashman L, Jaycox L, Perry K. The validation of a self-report measure of posttraumatic stress disorder: The posttraumatic diagnostic scale. Psychological Assessment 1997; 9: 445-451.

21. Reynolds WM. Suicide ideation questionnaire: Professional manual. Odessa, FL: Psychological Assessment Resources; 1991.

22. Steyn $R$, Nel JE. The effectiveness of psychometric selection criteria to reject applicants with high levels of suicide ideation from enlistment in the South African Police Service. Acta Criminologica 2008; 21 (1): 11-18.

23. Reynolds WM. Psychometric characteristics of the adult suicide ideation questionnaire with college students. Journal of Personality Assessment 1991; 56 : 289-307.

24. Osman A, Kopper BA, Linehan MM, Barrios FX, Gutierrez PM, Bagge CL. Validation of the suicide ideation questionnaire and the response for living inventory in an adult psychiatric inpatient sample. Psychological Assessment 1999; 11:115-123.

25. Spatz C, Kardas EP. Research methods in psychology: Ideas, techniques and reports. Boston, MA: McGraw-Hill; 2008.

26. Ben-Ya'acov Y, Amir M. Posttraumatic symptoms and suicide risk. Personality and Individual Differences 2004; 36:1257-1264.

27. Nye EC, Bell JB. Specific symptoms predict suicidal ideation in Vietnam combat veterans with chronic post traumatic stress disorder. Military Medicine 2007; 172(11): 1144-1147.

28. Selye H. The stress of life. New York: McGraw-Hill; 1956.

29. Rutz W, Rihmer Z. Suicide in men: Suicide prevention for the male person. In: Wasserman D, Wasserman C, editors. Oxford textbook of suicidology and suicide prevention. Oxford: Oxford University Press; 2009.

30. Elhai JD, Carvalho L, Miguel FC, Palmieri PA, Primi R, Frueh BC. Testing whether post-traumatic stress disorder and major depressive disorder are similar or unique constructs. Journal of Anxiety Disorders [internet]. Forthcoming 2011. Doi:10.1016/j.janxdis.2010.11.003.

31. LaMontagne AD, Keegel T, Louie AM Ostry A. Job stress as a preventable upstream determinant of common mental disorders: A review for practitioners and policy-makers. Advances in Mental Health 2010; 9(1): 17- 35. 